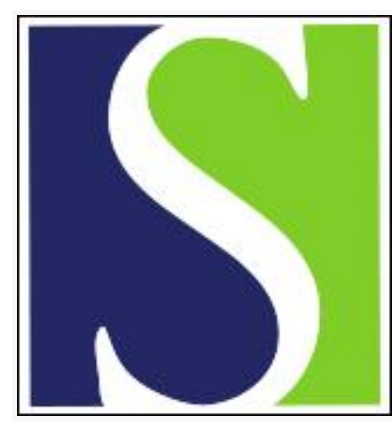

Scand J Work Environ Health 1986;12(3):216-220

https://doi.org/10.5271/sjweh.2155

Issue date: Jun 1986

Chronic effects of dichloromethane on amino acids, glutathione and phosphoethanolamine in gerbil brain.

by Briving $\mathrm{C}$, Hamberger A, Kjellstrand P, Rosengren L, Karlsson JE, Haglid KG

This article in PubMed: www.ncbi.nlm.nih.gov/pubmed/3749836

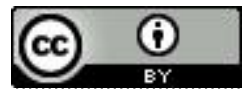




\title{
Chronic effects of dichloromethane on amino acids, glutathione and phosphoethanolamine in gerbil brain
}

\author{
by Carin Briving, PhD, ${ }^{1}$ Anders Hamberger, MD, ${ }^{1}$ Per Kjellstrand, PhD, ${ }^{2}$ \\ Lars Rosengren, MD, ${ }^{1}$ JE Karlsson, ${ }^{1}$ Kenneth G Haglid, MD ${ }^{1}$
}

\begin{abstract}
BRIVING C, HAMBERGER A, KJELLSTRAND P, ROSENGREN L, HAGLID KG. Chronic effects of dichloromethane on amino acids, glutathione and phosphoethanolamine in gerbil brain. Scand $J$ Work Environ Health 12 (1986) 216-220. Mongolian gerbils were exposed to dichloromethane for three months by continuous inhalation at $210 \mathrm{ppm}$. Total free tissue amino acids, glutathione, and phosphoethanolamine were determined in the vermis posterior of the cerebellum and the frontal cerebral cortex. These two brain areas were chosen because humans occupationally exposed to dichloromethane have shown abnormalities in the electroencephalogram of the frontal part of the cerebral cortex. This study showed that long-term exposure of gerbils to dichloromethane $(210 \mathrm{ppm})$ for three months leads to decreased levels of glutamate, $\gamma$-aminobutyric acid, and phosphoethanolamine in the frontal cerebral cortex, while glutamine and $\gamma$-aminobutyric acid are elevated in the posterior cerebellar vermis.
\end{abstract}

Key terms: experimental work, frontal cerebral cortex, long-term dichloromethane exposure, posterior cerebellar vermis.

Dichloromethane (methylene chloride, $\mathrm{CH}_{2} \mathrm{Cl}_{2}$ ) is used for a variety of purposes, as a solvent, a degreasing agent, an aerosol propellant, a paint remover, and as an extractant in the food industry. The adverse effects associated with dichloromethane exposure are primarily neurological and cardiovascular, while hepatotoxicity and nephrotoxicity are less pronounced. The effects on the central nervous system (CNS) are related to the anesthetic properties of the solvent. In cases of accidental human exposure, CNS symptoms include fatigue, nausea, headache, labored breathing, and unconsciousness. Behavioral alterations following acute exposure have also been described (29). Few experimental studies have concerned the chronic effects of dichloromethane on the CNS. Intermittent exposure of rats to dichloromethane $(500-1000 \mathrm{ppm})$ for two weeks causes neurochemical changes, including signs of increased protein breakdown in the cerebrum (26). We have previously shown that long-term exposure to moderate levels of trichloroethylene and perchloroethylene alters uptake and levels of amino acids in discrete brain regions of the gerbil (4).

This study reports on dichloromethane-induced effects on the nervous system of gerbils exposed for three months to the solvent at $210 \mathrm{ppm}$. The Swedish hygienic standard value is $70 \mathrm{ppm}$. The present work is part of an extended study on discrete brain areas, previously shown to be sensitive to chlorinated aliphatic solvents $(8,23)$. Concentrations of free amino

1 Institute of Neurobiology, University of Göteborg, S-400 33 Göteborg, Sweden.

2 Institute of Zoophysiology, University of Lund, S-223 62 Lund, Sweden.

Reprint requests to: Dr KG Haglid, Institute of Neurobiology, University of Göteborg, POB 33 031, S-400 33 Göteborg, Sweden. acids, glutathione, and phosphoethanolamine have been followed in the search for functional correlates to the recently reported alterations in cell composition of the CNS upon chronic exposure to dichloromethane (23).

\section{Materials and methods}

\section{Animal exposure}

The material consisted of four groups of Mongolian gerbils (eight animals in each), all the exposed animals being sex-matched littermates of the control animals. The animals were four months old when the exposure started. Two groups were exposed to $210 \mathrm{ppm}$ of dichloromethane by continuous inhalation. Two control groups were exposed to air in identical chambers. The environmental temperature was $22 \pm 2^{\circ} \mathrm{C}$. Commercial laboratory rat chow (Astra/Ewos, Sweden) and water were freely available.

The solvent (Uddeholm AB, Sweden) was vaporized at $60^{\circ} \mathrm{C}$ and diluted with filtered $(0.3 \mu \mathrm{m})$ air. The concentration of the solvent in the inhalation chambers was monitored with a Miran 1A spectrophotometer equipped with a multipath gas cell, and it was kept within $\pm 10 \%$ of the desired level. The exposure was interrupted for $1-2 \mathrm{~h}$ per week for changes of water, bedding material, and food (9).

After three weeks of exposure, eight exposed and eight control animals were removed from the inhalation chamber and immediately bled for the determination of carboxyhemoglobin percent saturation. After three months, eight exposed and their eight littermate controls were decapitated in the order control-exposed. The brains were rapidly removed and dissected as previously described (8). The vermis posterior of the cere- 
bellum (lobulus VI-X) and the frontal cerebral cortex were used for the determination of total free-tissue amino acids, glutathione, and phosphoethanolamine.

\section{Tissue content of free amino acids}

The dissected brain areas were extracted in $70 \%$ ethanol for $24 \mathrm{~h}$ at $+4^{\circ} \mathrm{C}$. The resulting extracts were stored at $-20^{\circ} \mathrm{C}$ until analyzed. The free amino acids were measured with reversed-phase liquid chromatography (Varian 5000 LC) after precolumn derivatization $(10,15)$. Briefly, a sample of the diluted tissue extract was mixed with borate buffer $(\mathrm{pH} \mathrm{12)}$, $o$-phthaldialdehyde, and mercaptoethanol. The mixture was injected onto a nucleosil $5 \mathrm{C}_{18}$ column after $1 \mathrm{~min}$. The effluent was monitored fluorimetrically (FS 970 LC fluorimeter, Schoeffel Instrument). The mobile phase was a gradient from $30-100 \%$ methanol in 0.04 $\mathrm{M}$ phosphate buffer, pH 5.2. Protein was determined according to Lowry et al (15).

\section{Determination of carboxyhemoglobin}

Four male littermate pairs of gerbils were continuously exposed to dichloromethane (210 ppm) for three weeks.
Four male littermate pairs of gerbils served as controls exposed to clean air. At the end of the exposure, the animals were removed from the inhalation chambers and immediately bled. The carboxyhemoglobin percent saturation was determined according to Collins et al (6) as modified by Lundh et al (16).

\section{Statistical evaluation}

The statistical analysis was performed with the aid of the Student's t-test for dependent series.

\section{Results}

\section{Body and brain weights}

The body and whole brain weights, as well as the weights of the dissected tissue pieces, did not differ significantly between the control and solvent-exposed groups (not shown).

\section{Levels of free amino acids, proteins, glutathione} and phosphoethanolamine

The protein concentrations per wet weight in different brain areas were not significantly altered after expo-

\section{FRONTAL CORTEX}

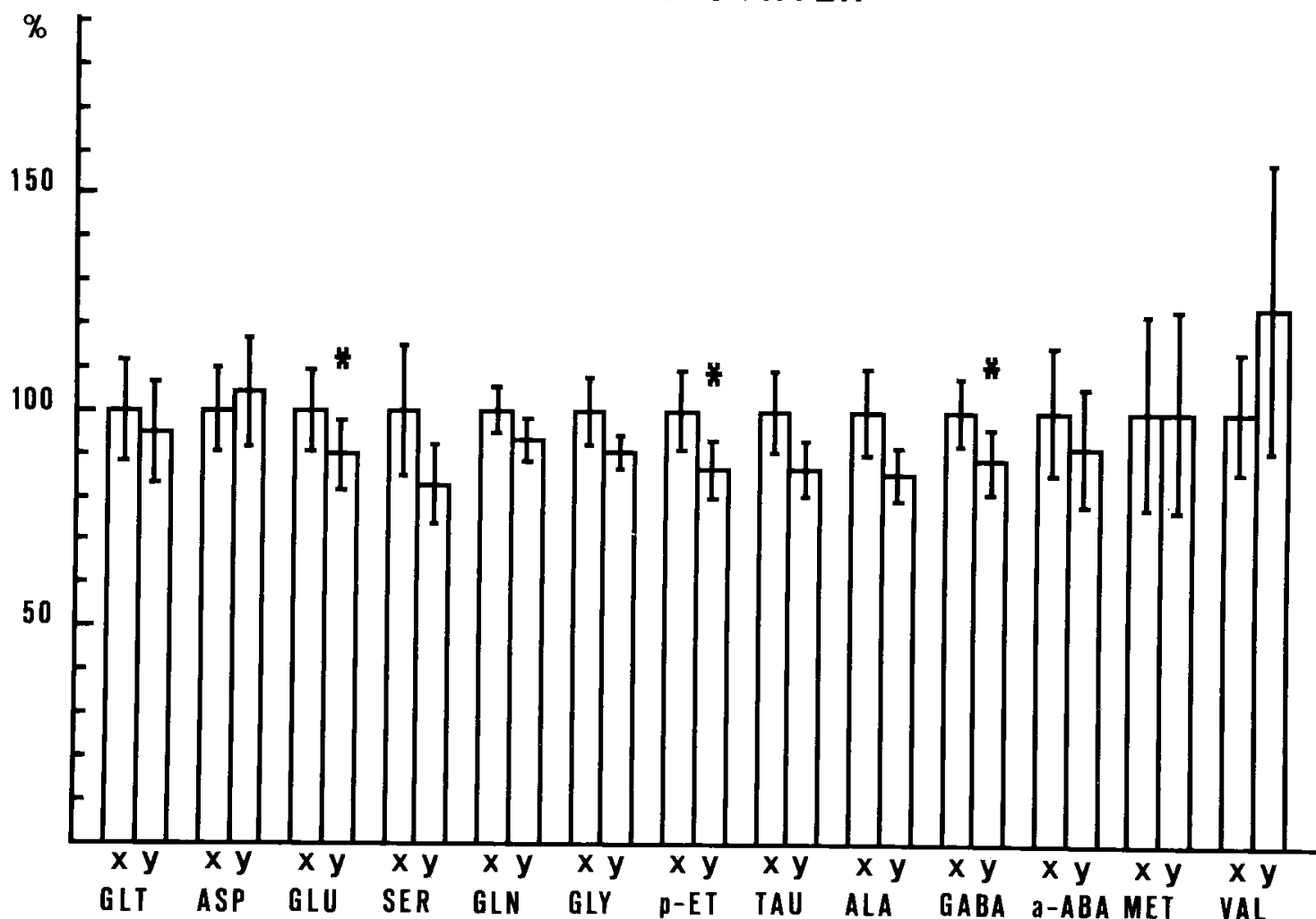

Figure 1. Content of different amino acids, glutathione, and phosphoethanolamine in the frontal cerebral cortex of gerbils immediately after continuous exposure to dichloromethane (210 ppm) for three months. Eight animals have been studied in each group, and the contents of amino acids have been estimated by the high-pressure liquid chromatographic technique. The results are given as the percentage of the control value. The statistical evaluation has been carried out with the aid of the Student's paired t-test $(* \mathrm{p}<0.05)$. $(X=$ control, $Y=$ exposed, GLT $=$ glutathione, $A S P=$ aspartate, GLU $=$ glutamate, $S E R=$ serine, $\mathrm{GLN}=$ glutamine, GLY = glycine, $\mathrm{p}-\mathrm{ET}=$ phosphoethanolamine, TAU = taurine, $A L A=$ alanine, GABA $=\gamma$-aminobutyric acid, a-ABA $=\alpha$-aminobutyric acid, MET $=$ methionine, $\mathrm{VAL}=$ valine) 


\section{VERMIS POSTERIOR}

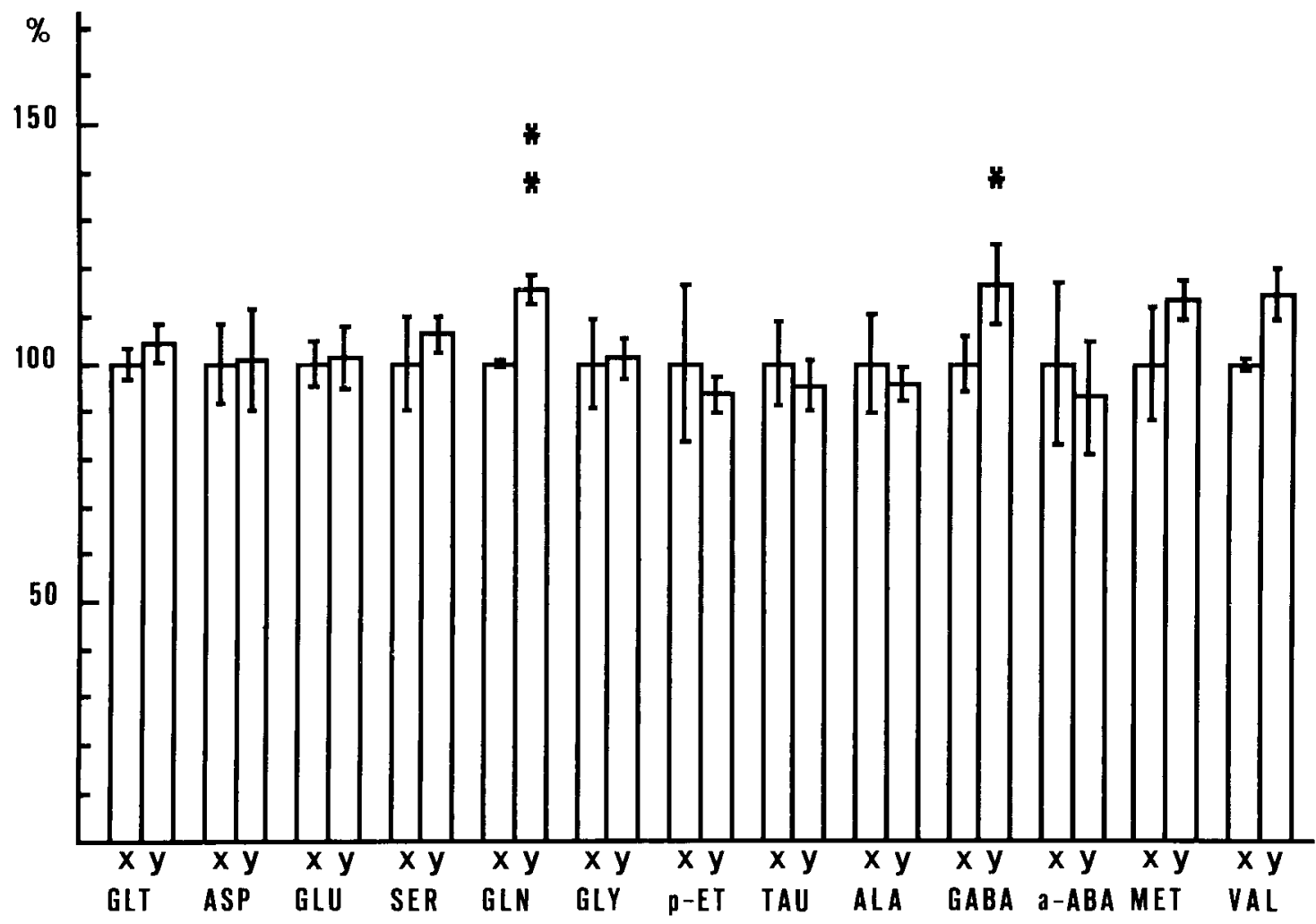

Figure 2. Amino acids, glutathione, and phosphoethanolamine content in the posterior cerebellar vermis after continuous exposure to dichloromethane $(210 \mathrm{ppm})$ for three months. The result has been obtained from the same animals as in figure 1. Statistical evaluations are also the same as in figure $1\left(^{*} p<0.05,{ }^{* *} p<0.01\right)$.

sure to dichloromethane. The means of the free amino acids in the posterior vermis of control gerbils were somewhat lower (4) than in earlier studies on rat (10). Glutamate, phosphoethanolamine, and $\gamma$-aminobutyric acid (GABA) were significantly decreased in the frontal cerebral cortex after the exposure to dichloromethane (figure 1). A different pattern of alterations was found in the cerebellar posterior vermis, eg, increased levels of glutamine and $\gamma$-aminobutyric acid (figure 2).

\section{Carboxyhemoglobin content}

After three weeks of exposure at $210 \mathrm{ppm}$ the carboxyhemoglobin percent saturation was significantly increased [11.5 (SE 0.4)] when compared to that of the controls [0.43 (SE 0.01)] ( $\mathrm{p} \leq 0.001)$.

\section{Discussion}

Long-term exposure to dichloromethane induces effects which differ markedly in two brain areas. When gerbils are exposed to a higher dose of dichloromethane $(350 \mathrm{ppm})$ for two months, long-lasting astrogliotic changes are induced and are traceable four months after exposure, especially in the frontal cerebral cortex (23).
After inhalation, dichloromethane is rapidly absorbed and distributed to the major body compartments. The absorbed solvent is mainly eliminated by pulmonary excretion of the unaltered parent compound. In the rat, about $50 \%$ of the absorbed dichloromethane is metabolized before elimination at higher exposure concentrations, whereas essentially all may be metabolized at lower exposure concentrations (18). Two major metabolic pathways of biotransformation have been demonstrated in rat liver. The first pathway described follows oxidation by the microsomal cytochrome P-450 monooxygenases and ultimately yields carbon monoxide (12). The second follows conjugation to glutathione and leads to the formation of formaldehyde (1). Carbon monoxide and carbon dioxide are the main metabolites in exhaled air (18). A covalent binding of metabolites of ${ }^{14} \mathrm{C}$-dichloromethane has been demonstrated in rat liver preparations (2).

One of the toxicologic hazards has been suggested to be brain dysfunction induced by carbon monoxide (3). The carboxyhemoglobin levels were significantly elevated among gerbils exposed to dichloromethane for three weeks. The relationship between the metabolism of dichloromethane and neurotoxicity of the compound is not fully understood. As both the major pathways of dichloromethane metabolism are present 
to some extent in rat brain $(1,17)$, local metabolite formation could be of importance in explaining the neurotoxicity of the compound. One metabolite, formaldehyde, formed after conjugation to glutathione, is a well-recognized toxin which is known to bind covalently to tissue macromolecules (5). However, the levels of glutathione were unaffected in the exposed animals. Furthermore, the toxicologic hazards of dichloromethane in rodent brain could depend on the lipophilic properties of the compound or on its intrinsic toxicity. Dichloromethane is, however, less lipid-soluble than other chlorinated organic solvents with known neurotoxicologic potentials, such as trichloroethylene and tetrachloroethylene (25).

In man, certain brain areas are more vulnerable to chronic dichloromethane exposure, eg, the anterior parts of the cerebral cortex (28). Our previous studies also indicate that different cerebellar brain areas of the gerbil are less sensitive towards dichloromethane exposure (23). The observed decreased levels of glutamate, $\gamma$-aminobutyric acid, and phosphoethanolamine in the frontal cerebral cortex after dichloromethane exposure are of interest in comparison with our previous results indicating that the frontal cerebral cortex is especially vulnerable (23). It has recently been reported that the $\gamma$-aminobutyric acid contents are markedly reduced in cerebral and cerebellar cortex in patients with encephalopathy upon repeated hemodialysis (20). The significance of the effect on phosphoethanolamine is presently not clear. However, this primary amine is extensively released from CNS areas in experimental epilepsy, hypoglycemia, and ischemia (7, $13,24)$. The increased levels of glutamine in the posterior cerebellar vermis could reflect an activation of astrocytic glia, as glutamine synthetase is localized exclusively in astrocytes (19). Alternatively, the increased glutamine could be secondary to the hyperammonemia caused by alterations in the liver due to dichloromethane. However, the liver toxicity of dichloromethane is considered to be low (21). The present results are in accordance with those of Honma et al (11), ie, increased CNS glutamine after one month's exposure to various levels of perchloroethylene $(400-800 \mathrm{ppm})$ or in the posterior cerebellar vermis after longer exposure periods at lower concentrations (4). The increased levels of $\gamma$-aminobutyric acid in the posterior cerebellar vermis after dichloromethane exposure might indicate solvent interaction with inhibitory neuronal pathways with consequences for the cerebellar regulation of body movements. It has been shown that acute exposure to dichloromethane results in a depression of the vestibulo-oculomotor reflex (VOR) in rats (27). This effect could be due to interactions with the cerebellar inhibition of this reflex (22). Consequently, our findings indicate that brain regions in the gerbil show specific patterns with regard to alterations in amino acid levels, as well as phosphoethanolamine, upon dichloromethane exposure. It is of particular interest that the neurotransmitter group of amino acids is affected. The decreased levels of $\gamma$-aminobutyric acid, glutamine, and phosphoethanolamine observed in the frontal cerebral cortex might be a more serious sign of interaction than the elevated levels of glutamine and $\gamma$-aminobutyric acid observed in the posterior cerebellar vermis, since this brain area seems to be less sensitive towards dichloromethane exposure (23).

\section{Acknowledgments}

This work was supported by the Swedish Work Environmental Fund (grant 84-0217 and 85-0585).

Ms E Åwall is gratefully acknowledged for her skillful technical assistance. We thank Ms G Grönstedt for typing the manuscript.

\section{References}

1. Ahmed AE, Anders MW. Metabolism of dihalomethanes to formaldehyde and inorganic halide: I In vitro studies. Drug Metab Dispos 4 (1976) 357-361.

2. Anders MW, Kubic VL, Ahmed AE. Metabolism of halogenated methanes and macromolecular binding. $J$ Environ Pathol Toxicol 1 (1977) 117-124.

3. Barrowcliff DF, Knell AJ. Cerebral damage due to endogenous chronic carbon monoxide poisoning caused by exposure to methylene chloride. J Soc Occup Med 29 (1979) $12-14$.

4. Briving C, Jacobson I, Hamberger A, Kjellstrand P, Rosengren L, Haglid KG. Chronic effects of perchloroethylene and trichloroethylene on the gerbil brain amino acids and glutathione. Neurotoxicology (in press).

5. Casanova-Schmitz M, Starr TB, Heck Hd'A. Differentiation between metabolic incorporation and covalent binding in the labeling of macromolecules in the rat nasal mucosa and bone marrow by inhaled $\left({ }^{14} \mathrm{C}\right)$ - and $\left({ }^{3} \mathrm{H}\right)$ formaldehyde. Toxicol Appl Pharmacol 76 (1984) 26-44.

6. Collins HA, Rodkey FL, O'Neal JD. Determination of carbon monoxide in blood by gas chromatography. Clin Chem 14 (1968) 162-171.

7. Hagberg H, Lehmann A, Sandberg M, Nyström B, Jacobson I, Hamberger A. Ischemia-induced shift of inhibitory and excitatory amino acids from intra- to extracellular compartments. J Cereb Blood Flow Metab (in press).

8. Haglid $\mathrm{KG}$, Briving $\mathrm{C}$, Hansson $\mathrm{H}-\mathrm{A}$, Kjellstrand $\mathrm{P}$, Rosengren LE, Stavrou D, Swedin U, Wronski A. Trichloroethylene: Long-lasting changes in the brain after rehabilitation. Neurotoxicology 4 (1981) 659-673.

9. Haglid KG, Kjellstrand P, Rosengren L, Wronski A, Briving C. Effects of trichloroethylene inhalation on proteins of the gerbil brain. Arch Toxicol 43 (1980) 187199.

10. Hamberger A, Jacobson I, Lindroth P, Mopper K, Nyström B, Sandberg M, Molin S-O, Svanberg U. Neuronglia interactions in the biocynthesis and release of transmitter amino acids. Adv Biochem Psychopharmacol 29 (1981) 509-518.

11. Honma $T$, Hasegawa $H$, Sato $M$, Sudo A. Changes of free amino acid content in rat brain after exposure to trichloroethylene and tetrachloroethylene. Ind Health 18 (1980) $1-7$.

12. Kubic VL, Anders MW. Metabolism of dihalomethanes to carbon monoxide: II In vitro studies. Drug Metab Dispos 3 (1975) 104-112.

13. Lehmann A, Hagberg H, Jacobson I, Hamberger A. 
Effects of status epilepticus on extracellular amino acids in hippocampus. Brain Res (in press).

14. Lindroth $\mathrm{P}$, Mopper K. High-performance liquid chromatographic determination of subpicomole amounts of amino acids by precolumn fluorescence derivatization by o-phthaldialdehyde. Anal Chem 51 (1979) 16671674.

15. Lowry OH, Rosebrough NJ, Farr AL, Randall RJ. Protein measurement with the Folin phenol reagent. J Biol Chem 193 (1951) 265-275.

16. Lundh B, Johansson MB, Mercke C, Cavallin-Stăhl E. Enhancement of heme catabolism by caloric restriction in man. Scand J Clin Lab Invest 30 (1972) 421-427.

17. Marietta MP, Vesell ES, Hartman RD, Weisz J, Dvorchik BH. Characterization of cytochrome P-450-dependent aminopyrine $\mathrm{N}$-demethylase in rat brain: Comparison with hepatic aminopyrine $\mathrm{N}$-demethylation. $\mathrm{J}$ Pharmacol Exp Ther 208 (1979) 271-279.

18. McKenna MJ, Zempel JA, Braun WH. The pharmacokinetics of inhaled methylene chloride in rats. Toxicol Appl Pharmacol 65 (1982) 1-10.

19. Norenberg MD, Martinez-Hernandez A. Fine structural localizations of glutamine synthetase in astrocytes of rat brain. Brain Res 161 (1979) 303-310.

20. Perry TL, Young VW, Kish SJ, Foulks JG, Godolphin WJ, Sweeney VP. Neurochemical abnormalities in brains of renal failure patients treated by repeated hemodialysis. J Neurochem 4 (1985) 1043-1048.

21. Plaa GL, Larsson RE. Relative nephrotoxic properties of chlorinated methane, ethane and ethylene derivatives in mice. Toxicol Appl Pharmacol 7 (1965) 37-44.
22. Precht W. Vestibular mechanisms. Ann Rev Neurosci 2 (1979) 265-289.

23. Rosengren LE, Kjellstrand P, Aurell A, Haglid KG. Irreversible effects of dichloromethane on the brain after long-term exposure: A quantitative study of DNA and the glial cell marker proteins S-100 and GFA. Br J Ind Med (in press).

24. Sandberg M, Nyström B, Hamberger A. Metabolically derived aspartate-elevated extracellular levels in vivo in iodoacetate poisoning. J Neurosci Res 13 (1985) 489 495.

25. Sato A, Nakajima T. Partition coefficients of some aromatic hydrocarbons and ketones in water, blood and oil. Br J Ind Med 36 (1979) 231-234.

26. Savolainen H, Kurppa K, Pfäffli P, Kivistö H. Doserelated effects of dichloromethane on rat brain in shortterm inhalation exposure. Chem Biol Interact 34 (1981) $315-322$

27. Tham R, Bunnfors I, Eriksson B, Larsby B, Lindgren $\mathrm{S}$, Ödkvist LM. Vestibulo-ocular disturbances in rats exposed to organic solvents. Acta Pharmacol Toxicol 54 (1984) $58-63$.

28. Von Hanke C, Ruppe K, Otto J. Untersuchungsergebnisse zur toxischen Wirkung von Dichlormetan bei Fussbodenlegern. Z Gesamte Hyg 20 (1974) 81-84.

29. Winek CL, Collom WD, Esposito F. Accidental methylene chloride fatality. Forensic Sci Int 18 (1981) $165-168$.

Received for publication: 7 November 1985 